\title{
Mucopolissacaridose: características e alterações bucais
}

\author{
Mucopolysaccharidosis: characteristics and oral changes
}

Claudia Marcela Hernández Cancino*
Isabel Nemoto Vergara Sasada**
Carolina Fischinger Moura de Souza ${ }^{* * *}$
Marieli Oliveira

\section{Resumo}

Objetivo: realizar uma revisão de literatura sobre as mucopolissacaridoses, abordando as características sistêmicas associadas às bucais, e, assim, possibilitar um tratamento odontológico adequado e uma melhor qualidade de vida aos pacientes. Revisão de literatura: a mucopolissacaridose é uma desordem metabólica hereditária, causada por erros inatos do metabolismo que provocam deficiência das enzimas lisossômicas que degradam os glicosaminoglicanos, ocasionando acúmulo destes no interior dos diferentes tecidos e órgãos. Esse acúmulo anormal compromete a função celular e orgânica, levando a um grande número de manifestações clínicas progressivas e multissistêmicas. As manifestações orais variam de acordo com o tipo de mucopolissacaridoses e são bastante significativas. Em sua maioria, os indivíduos apresentam boca grande, lábios proeminentes, macroglossia, mordida aberta anterior, mandíbula pequena e larga, limitação da abertura bucal, hiperplasia gengival, respiração bucal, impacção dentária, hipoplasia do esmalte, diastemas com relativa microdontia, taurodontismo, hiperplasia dos folículos dentais e cistos dentígeros. $O$ acompanhamento deve ser multidisciplinar e mantido ao longo do tempo, monitorando-se a evolução do paciente, prevendo-se qualquer complicação e corrigindo-se as disfunções que se apresentarem, bem como se avaliando a eficácia da terapia instituída. Considerações finais: são inúmeras as manifestações bucais, portanto, é necessário que o profissional conheça as mucopolissacaridoses e que acompanhe o paciente desde a infância até a fase adulta, objetivando a prevenção, a manutenção da saúde bucal, o atendimento especializado e multidisciplinar.

Palavras-chave: Mucopolissacaridose. Patologia. Saúde bucal.

\section{Introdução}

As mucopolissacaridoses (MPSs) formam um grupo de doenças lisossômicas provocadas pela deficiência das enzimas responsáveis pela degradação dos glicosaminoglicanos (GAGs). O acúmulo de mucopolissacarídeos nas células causa sintomas progressivos em órgãos e tecidos, especialmente ossos, fígado, cérebro, coração, entre outros ${ }^{1-3}$.

A maioria dessas doenças é de herança autossômica recessiva. Ao nascimento, os portadores apresentam fenótipo normal, mas com a progressão do acúmulo ocorrem importantes e permanentes alterações celulares, que afetam a aparência, a capacidade física, o funcionamento sistêmico e, algumas vezes, o desenvolvimento neurológico ${ }^{1-4}$. Em todos os tipos de MPS, é frequente a ocorrência de macrocefalia, opacificação da córnea, hepatoesplenomegalia, hérnia umbilical e inguinal, displasia óssea, atraso no desenvolvimento motor, hipoacusia, dificuldade respiratória, alterações faciais e dentárias, macroglossia, cardiopatia, limitação da mobilidade articular, subluxação do quadril e coxa valga, entre outras características, conforme o tipo de MPS. A expectativa de vida é reduzida devido às complicações clínicas associadas, principalmente, às cardiorrespiratórias ${ }^{1,2,5}$.

Na cavidade bucal, as características que têm sido descritas são: boca grande, lábios proeminentes, macroglosia, mordida aberta anterior, limitação da abertura bucal, hiperplasia gengival, respiração bucal, inclusão dentária, diastemas, microdontia, obliteração das câmaras pulpares, hiperplasia dos folículos dentários e cistos dentígeros ${ }^{6,7}$.

\footnotetext{
Doutora em Cirurgia e Traumatologia Bucomaxilofacial. Professora do Curso de Especialização em Odontologia para Pacientes com Necessidades Especiais da ABO-RS.

Mestre em Saúde da Criança e do Adolescente. Coordenadora do Curso de Especialização em Odontologia para Pacientes com Necessidades Especiais da ABO-RS.

** Doutora em Genética e Biologia Molecular. Coordenadora do Programa de Genética Médica do Hospital de Clínicas de Porto Alegre.

*** Especialista em Odontologia para Pacientes com Necessidades Especiais da ABO-RS.
} 
O objetivo desta revisão de literatura é abordar as características sistêmicas e odontológicas das MPSs, de forma a destacar a importância do atendimento especializado e multidisciplinar que possibilite o planejamento e o manejo adequado dos doentes.

\section{Revisão de literatura}

A mucopolisacaridose (MPS) caracteriza-se pela deficiência de uma ou mais enzimas lisossômicas necessárias para a degradação dos GAGs, ocorrendo acúmulo no interior das células e a excreção do excesso pela urina do paciente. Os indivíduos acometidos apresentam uma variedade de alterações sistêmicas, com sinais e sintomas que dependem do grau de severidade da doença. Os achados clínicos mais comuns são: hepatoesplenomegalia, feições grosseiras, retardo de crescimento, anormalidades ósseas, macrocefalia, deficiência de audição, opacificação da córnea, hérnia inguinal e umbilical, cardiopatia e, em alguns casos, degeneração neurológica ${ }^{6,8,9}$.

Conforme a Sociedade Brasileira de Mucopolissacaridoses, são reconhecidos onze tipos diferentes: MPS I, MPS II, MPS III-A, MPS III-B, MPS III-C, MPS III-D, MPS IV-A, MPS IV-B, MPS VI, MPS VII e MPS IX ${ }^{9}$. A classificação depende da deficiência enzimática específica, existindo heterogeneidade de fenótipos devido às diversas mutações que ocorrem dentro do mesmo grupo, bem como fenótipos semelhantes em diferentes tipos de MPS $^{9,10}$.

A herança é autossômica recessiva, com exceção da MPS do tipo II - Síndrome de Hunter -, que é ligada ao cromossomo $\mathrm{X}$, acometendo, na sua maioria, os homens ${ }^{10}$. Em todas essas doenças, com exceção da MPS III-C, a deficiência enzimática encontrada é de enzimas hidrolases ${ }^{10,11}$.

A incidência de MPS varia de 1,9 a 4,5 casos em 100.000 nascimentos no mundo ${ }^{9}$. A expectativa de vida nas formas graves é até a primeira década, porém, nas formas atenuadas, a sobrevida pode ser normal. A causa da morte, geralmente, é por obstrução das vias aéreas ou insuficiência cardíaca ${ }^{9,10}$.

\section{Mucopolisacaridose Tipo I - Síndrome de Hurler, de Scheie e de Hurler-Scheie}

A mucopolisacaridose tipo I é causada pela deficiência ou ausência da enzima alfa-L-iduronidase, que tem a função de degradar os GAGs heparan sulfato e dermatan sulfato, presentes, em sua maioria, no sistema nervoso central, tecidos de conexão, coração, esqueleto e córnea ${ }^{11}$.

A Síndrome de Scheie é a forma mais atenuada, representando um grau de comprometimento e severidade mais brando. Nessa subclassificação, o paciente apresenta a inteligência preservada com uma expectativa de vida até a fase adulta. A Síndrome de Hurler é a forma mais grave das MPSs, pois os indivíduos apresentam um declínio neuro- degenerativo progressivo, ocasionando uma importante deficiência cognitiva. O prognóstico é sombrio, com uma expectativa de vida de até uma década. A Síndrome de Hurler-Scheie é a combinação genética das duas síndromes e tem grau de severidade intermediário. Nessa forma, quem possui a doença apresenta a inteligência normal ou deficiência mental leve. $\mathrm{O}$ início dos sinais e sintomas ocorre entre 3 e 8 anos de idade, após esse período, há um sensível decréscimo no crescimento $0^{6,10,12}$.

As características clínicas observadas são mãos em garra, traços fisionômicos grosseiros, redução da mobilidade articular, baixa estatura, opacificação da córnea, hisurtismo, mãos e pés pequenos e largos, ossos curtos e deformados, dilatação da caixa torácica, hepatoesplenomegalia, hérnia umbilical e inguinal, surdez em diversos graus, anomalias cardíacas, otite média recorrente, problemas respiratórios e hidrocefalia, em alguns $\operatorname{casos}^{6,12,13}$. A incidência mundial da MPS I é de 1:100.000 em nascidos vivos ${ }^{10,14,15}$.

\section{Mucopolissacaridose tipo II - Síndrome de Hunter}

Os sujeitos acometidos por essa síndrome são os homens, devido à herança genética ser ligada ao cromossomo X. Eles apresentam deficiência da enzima iduronato-2-sulfatase responsável pela degradação dos GAGs sulfato de heparan e sulfato de dermatan, presentes, em sua grande maioria, no sistema nervoso central, tecidos de conexão, coração, esqueleto e córnea ${ }^{11,13}$.

A MPS II é classificada de duas formas. A MPS II-A é a mais grave ou neuropática, pois o sistema nervoso central é acometido, causando retardo mental, deterioração física progressiva e morte precoce. A MPS II-B é a forma leve ou não neuropática, já que não há envolvimento do sistema nervoso central e os pacientes podem chegar à fase adulta ${ }^{6,13}$.

Os acometidos também apresentam baixa estatura, disostoses ósseas múltiplas, rigidez articular, traços fisionômicos grosseiros, disfunções respiratórias causando infecções recorrentes e apneia do sono, hérnia umbilical e inguinal, comportamento hiperativo e agressivo, espasticidade, macrocefalia, surdez progressiva e otites recorrentes, hepatoesplenomegalia e, ocasionalmente, síndrome do túnel do carpo, compressão da medula espinhal, hidrocefalia e episódios convulsivos ${ }^{6-13}$.

\section{Mucopolissacaridose tipo III - Síndrome de San Fillippo}

Na mucopolissacaridose tipo III, ocorre regressão do desenvolvimento neuropsicomotor entre 2 e 6 anos de idade. O GAG heparan sulfato, que é encontrado, principalmente, no sistema nervoso central, quando em excesso na urina, indica o diagnóstico dessa doença; causada por quatro defeitos 
enzimáticos. Na MPS III-A, a enzima deficiente é a heparan-N-sulfatase; na MPS III-B, é a alfa-N-acetilglucosaminidase; na MPS III-C, é a acetil-CoA-alfa-glucosamina; na MPS III-D, é a N-acetilglicosamina 6-sulfatase e,11,15,16. $^{6}$.

Nos quatro tipos da doença, o fenótipo clínico é idêntico. Pode-se observar a face discretamente grosseira, deficiência mental grave, distúrbio do sono, hiperatividade, envolvimento cardíaco, infecções frequentes das vias aéreas superiores, pele mais espessa e dura, hisurtismo com cabelo seco e áspero e hepatoesplenomegalia. Devido à gravidade das complicações de saúde encontradas, a expectativa de vida pode ser por volta de $20 \operatorname{anos}^{6,15}$.

\section{Mucopolissacaridose tipo IV - Síndrome de Morquio}

A mucopolissacaridose tipo IV é causada pela mutação de dois genes diferentes, mas com manifestações clínicas e morfológicas similares. As deficiências enzimáticas que definem os subtipos da doença são: na MPS IV-A, a enzima galactose-6-sulfatase, cuja função é quebrar o GAG queratan sulfato, encontrado em grande quantidade em: cartilagem, esqueleto, coração e córnea; na MPS IV-B, a enzima beta-galactosidase, também com função de quebra do GAG queratan sulfato, entretanto, esses indivíduos tendem a ser afetados mais levemente pela doença do que os indivíduos com MPS IV-A ${ }^{6,11,15}$.

$\mathrm{O}$ crescimento começa a desacelerar a partir dos 18 meses de vida, cessando no final da infância. A estatura é baixa, com pescoço e tronco curtos; o crescimento da coluna é alterado, mas o osso esterno cresce normalmente, dando a aparência de "peito de pombo". Em razão dessa conformação óssea diferenciada, os sujeitos apresentam dificuldade respiratória e, com isso, infecções recorrentes das vias aéreas e do ouvido. Na face, os traços são levemente grosseiros, há opacificação da córnea, as mãos são curtas, as articulações e os ligamentos apresentam frouxidão. Os pacientes também apesentam perda gradativa da audição, doença cardíaca e hérnias umbilical e inguinal. A inteligência é preservada ${ }^{6,15}$.

\section{Mucopolissacaridose tipo VI - Síndrome de Maroteaux-Lamy}

Na mucopolissacaridose tipo VI, há deficiência da enzima arilsulfatase $B$, que é essencial na quebra dos GAGs dermatan sulfato e condroitina sulfato, macromoléculas encontradas em maior quantidade em: esqueleto, córnea, vasos sanguíneos e coração. A gravidade pode variar de forma leve, intermediária ou grave. Os indivíduos com a forma mais grave podem ter uma deterioração rápida entre 3 e 6 anos, com uma expectativa de vida em torno dos 20 anos de idade. A inteligência é preservada ${ }^{6,11}$.
A manifestação clínica mais comum é a baixa estatura, variando entre menos de um metro de altura, para os pacientes com a forma mais grave, e um metro e cinquenta centímetros, para os adultos com a forma leve. Também apresentam pescoço curto, opacidade da córnea e glaucoma, face grosseira com ponte nasal achatada, hipertelorismo, macrocefalia acompanhada ou não de hidrocefalia, cardiopatias, surdez, rigidez articular e complicações respiratórias ${ }^{6,11,13}$.

\section{Mucopolissacaridose tipo VII - Síndrome de Sly}

A deficiência da enzima beta-glucoronidase, que degrada os GAGs dematan sulfato, condroitina sulfato e heparan sulfato, é o que caracteriza a MPS VII. O sistema nervoso central, esqueleto, coração e os tecidos de conexão são os locais em que esses GAGs se encontram, em sua grande maioria. Na Síndrome de Sly, as formas de fenótipos clínicos são diversas ${ }^{6,11}$.

Os pacientes apresentam anormalidades esqueléticas severas, deficiência mental moderada, atraso no crescimento, hepatoesplenomegalia, comprometimento das válvulas cardíacas, hidrocefalia, contraturas articulares, hidropisia fetal e displasia do quadril ${ }^{2,11,15}$.

\section{Mucopolissacaridose tipo IX}

Poucos casos de MPS IX foram relatados. A deficiência enzimática é de hialuronidase, que degrada o GAG ácido hialurônico, encontrado principalmente no tecido periarticular e meio extracelular ${ }^{6,11}$.

A manifestação clínica mais evidente é o problema articular. Ocorre a formação de massas nodulares em volta das articulações, que regridem em três dias, causando dores incapacitantes. Também são observados baixa estatura, feições da face grosseiras e inchaço cutâneo. Contudo, os movimentos e o desenvolvimento cognitivo são preservados ${ }^{6,11}$.

\section{Alterações odontológicas}

As manifestações orais são frequentemente detectadas em todos os tipos de MPS, principalmente, macroglossia, lábios proeminentes, palato profundo, mandíbula com pouca altura e com alteração de côndilos, gengiva hiperplásica, diastemas, dentes hipoplásicos, impactados, supranumerários, erupção ectópica, atraso na erupção e más oclusões seve$\operatorname{ras}^{6,10,15}$.

$\mathrm{Na}$ síndrome de Hurler (MPS I), a gengiva é hiperplásica, a mandíbula é curta, com os côndilos achatados, os pacientes também apresentam taurodontismo, raízes curtas e agenesias dentárias ${ }^{15}$. Múltiplos dentes impactados com o folículo dentário hiperplásico podem estar presentes. Acredita-se que a deficiência ou a ausência de certas enzimas 
no folículo dental, que são necessárias no período de erupção, seja o motivo causador da retenção dentária ${ }^{15}$. O atraso de erupção dos dentes e a inclusão de molares permanentes também são constatados com bastante frequência na MPS II (Síndrome de Hunter) e na MPS VI (Síndrome de Maroteaux Lamy). Isso acontece em decorrência da hiperplasia dos folículos dentais pelo excesso de acúmulo do GAG dermatan sulfato e do colágeno ${ }^{13,14,16}$.

O tecido gengival dos indivíduos com MPS II (Síndrome de Hunter) é hiperplásico, hipertrófico e espesso; a língua é grossa e maior do que o normal. Eles apresentam problemas com as tonsilas e adenoides e desenvolvem infecções respiratórias frequentes ${ }^{16}$.

Na MPS do tipo III (Síndrome de San Filippo), as alterações odontológicas são raras. Em alguns casos, foi detectada a obliteração das câmaras pulpares e dos canais radiculares por deposição de dentina secundária irregular e atraso na erupção dentária ${ }^{16}$. O lábio inferior pode ser grosso e evertido, enquanto o lábio superior apresenta-se caído, com um filtro protuberante. Os pacientes podem apresentar hipoplasia do esmalte e palato estreito e profundo ${ }^{15,16}$.

Os pacientes com MPS I (Síndrome de Hurler) e MPS IV (Síndrome de Morquio) podem apresentar alterações na estrutura do esmalte nas dentições decídua e permanente. Essa variação qualitativa na estrutura dos prismas de esmalte é observada por intermédio da microscopia eletrônica. Essa doença altera a mineralização dos ossos e do esmalte dentário, rompendo a organização dos cristais de esmalte, que mudam a sua orientação, apresentam-se com menor tamanho e menos anisotrópicos do que o esmalte sadio $^{7}$. A hipoplasia do esmalte também pode ocorrer e, devido à fragilidade, esse pode ser facilmente destacado da dentina. Acredita-se que esse fenômeno ocorre devido ao acúmulo do GAG queratan sulfato nos lisossomos dos ameloblastos que estão em fase de secreção do esmalte dentário ${ }^{7}$.

O desenvolvimento ósseo e dentário nos pacientes com MPS VI (Síndrome de Maroteaux Lamy) é bastante comprometido pela doença. Os côndilos mandibulares são hipoplásicos, a parte cartilaginosa da mandíbula é mais afetada do que a parte intramembranosa, uma vez que ocorre o acúmulo dos GAGs dermatan sulfato e condroitina sulfato, interferindo no desenvolvimento dos condrócitos. Esse fenômeno, juntamente com a macroglossia, provoca más oclusões dentárias severas, principalmente mordida aberta anterior ${ }^{16}$. Diastemas com relativa microdontia, hipertrofia dos processos alveolares e hiperplasia gengival também são alterações odontológicas encontradas nesses indivíduos ${ }^{6,9,15,16}$.

O aparecimento de cistos dentígeros bilaterais ou múltiplos está associado, com maior frequência, a MPS tipo VI (Síndrome de Maroteaux-Lamy) ${ }^{9}$, entretanto, também podem ocorrer nos pacientes com MPS I (Síndrome de Hurler) e MPS II (Síndrome de Hunter $)^{6}$. Esse é um cisto odontogênico que se origina pela separação do folículo da coroa de um dente incluso e está unido ao dente pela junção esmalte-cemento. A formação do cisto desloca os dentes envolvidos por distâncias consideráveis, podendo haver a reabsorção radicular dos dentes adjacentes. Um cisto dentígero não inflamado é caracterizado histologicamente por uma cápsula de tecido conjuntivo fibroso arranjado frouxamente, tecido conjuntivo folicular e a substância fundamental que contém um acúmulo de GAGs ${ }^{17}$.

Na MPS VII, as células mais afetadas são aquelas em que o turnover de macromoléculas é mais alto, como nos odontoblastos, ameloblastos e fibroblastos do ligamento periodontal. Extracelularmente, a pré-dentina apresenta fibras colágenas anormais e existem áreas com defeito na mineralização, tanto em esmalte quanto em dentina ${ }^{6,16}$.

A macroglossia é uma alteração presente em quase todos os tipos de MPS e pode causar deformidades dento-músculo-esqueletais e instabilidade no tratamento ortodôntico. Além disso, outros problemas também podem ser desenvolvidos, como mastigatórios, respiratórios, de paladar e fala ${ }^{16}$.

\section{Discussão}

O planejamento do tratamento odontológico deve ser baseado nos efeitos multissistêmicos que os pacientes com MPS apresentam. A atenção do cirurgião-dentista deve estar voltada para os problemas cardiorrespiratórios, neurológicos, musculoesqueléticos e para a percepção auditiva e visual, a fim de oferecer um atendimento efetivo, seguro e de qualidade ${ }^{1-3,6,12}$.

As anormalidades cardiovasculares são comumente encontradas nas MPS devido à infiltração progressiva de GAGs nos tecidos valvares, no miocárdio e na artéria coronária. Em função disso, intercorrências como arritmias, crises hipertensivas e infarto do miocárdio podem ocorrer durante o procedimento odontológico. Logo, a presença de sinais e sintomas de descompensação clínica deve ser sempre observada, interrompendo ou contraindicando o atendimento odontológico a qualquer momento, se necessário. Também é importante ressaltar o uso de profilaxia antibiótica para prevenir a endocardite bacteriana nos casos de procedimentos cruentos e em pacientes que exijam esse cuidado ${ }^{12}$.

Os problemas respiratórios surgem em decorrência das deformidades das cartilagens traqueais ou bronquiais, infiltração de GAGs nos tecidos da glote e limitação de mobilidade da caixa torácica. Além disso, os indivíduos com MPS possuem tonsilas e adenoides alargadas, rinite crônica e síndrome de apneia do sono. Recomenda-se que o tratamento odontológico seja realizado com o paciente posicionado o mais próximo de $90^{\circ}$, evitando a posição supina, para que se crie conforto respiratório. O odontólogo deve evitar prescrever ou usar substâncias que gerem broncoespasmo e estar atento a um possível quadro de crise aguda ${ }^{12,16}$. 
Acredita-se que a perda auditiva é decorrente da má-formação da cadeia ossicular do ouvido, da obstrução tubária, da otite média recorrente, da alteração do osso temporal e do espessamento do muco no ouvido médio; isso devido ao depósito de GAGs, ocorrendo alteração da condução do som. A comunicação entre o odontólogo e o paciente pode ser por contato visual, utilizando também diagramas ou desenhos explicativos. Os aparelhos auditivos devem ser removidos no momento da utilização de equipamentos ruidosos, pois esses são amplificadores de som e poderão tornar a consulta desconfortável ${ }^{12}$.

A perda visual ocorre pelo armazenamento de GAGs na córnea e na retina, causando degeneração dessas estruturas. O sintoma principal é a fotofobia junto com a perda progressiva da acuidade visual. Durante o procedimento odontológico, os equipamentos e instrumentos devem ser apresentados ao paciente por meio do tato, a fim de que seja evitada uma reação brusca inesperada diante de novas sensações que o tratamento pode provocar ${ }^{12}$.

No nível neurológico, alguns pacientes apresentam leve atraso do desenvolvimento neuropsicomotor nos primeiros anos de vida, enquanto outros têm uma deterioração cognitiva e sensorial progressiva. Os pacientes com deficiência mental leve ou moderada podem permitir o tratamento odontológico, entretanto, uma pessoa com deficiência mental severa, provavelmente, poderá resistir ao atendimento. Nesse último caso, o profissional pode utilizar condutas de condicionamento de comportamento e técnicas de contenção física ou anestesia geral. Geralmente, a sedação consciente com óxido nitroso está contraindicada nos pacientes com MPS, já que eles apresentam obstrução das vias aéreas ${ }^{12}$.

O tratamento odontológico e o plano de prevenção de saúde bucal devem levar em conta as dificuldades encontradas por esses pacientes para a higienização bucal. As alterações articulares limitam o movimento das mãos, dificultando a escovação dos dentes e o uso do fio dental. Ao mesmo tempo, características como a macroglossia e a má oclusão podem ser agravantes no quadro da saúde oral desses pacientes. A cárie e a doença periodontal em portadores de deficiência mental também estão associadas à dificuldade de higiene. $\mathrm{O}$ paciente deve ser estimulado a realizar a escovação sempre que lhe seja possível, utilizando escovas adequadas e adaptadas às necessidades e à capacidade do paciente ${ }^{12,15,16}$.

Pacientes com deficiências psíquicas, cognitivas ou com limitações físicas, assim como aqueles que têm suas habilidades motoras preservadas, que deambulam e conseguem manter-se em pé, geralmente, escovam os dentes sozinhos, mas precisam de supervisão para verificar a eficácia e a frequência da escovação.

A manutenção da saúde bucal melhora a qualidade de vida do indivíduo com MPS, por essa razão, é necessário implementar os cuidados preventivos como principal medida de promoção de saúde. Pro- gramar consultas frequentes ao cirurgião-dentista para manter com mais eficiência a boa condição de saúde bucal é o plano de tratamento ideal ${ }^{6}$.

\section{Considerações finais}

A MPS atinge vários tecidos e órgãos, causando sinais e sintomas multissistêmicos, por isso, exige no seu tratamento a presença de uma equipe de saúde multidisciplinar ao longo de toda a vida, já que não possui cura ainda.

Devem ser implantadas terapias que melhorem a qualidade de vida do paciente, visando a um cuidado multidisciplinar e, assim, controlando os sinais e os sintomas causados pelas complicações sistêmicas que o curso degenerativo e progressivo da MPS acarreta.

O tratamento odontológico é muito importante para a melhora da saúde do indivíduo, uma vez que já é comprovada a relação de muitas doenças sistêmicas com a saúde bucal. São muitas as alterações odontológicas que os pacientes com essa doença apresentam, por isso, necessitam do acompanhamento do cirurgião-dentista desde a infância, objetivando a prevenção das doenças bucais. Com o conhecimento técnico e científico amplo, o cirurgião-dentista pode oferecer qualidade no tratamento com comodidade e segurança ao paciente, tornando $o$ atendimento humanizado e individualizado.

\section{Abstract}

Objective: to perform a literature review on mucopolysaccharidosis addressing systemic characteristics associated with oral features, thus allowing a proper dental treatment and a better quality of life of the patient. Literature review: mucopolysaccharidosis is an inherited metabolic disorder caused by innate errors of metabolism, which cause the deficiency of lysosomal enzymes that degrade glycosaminoglycans and cause their accumulation within different tissues and organs. This abnormal accumulation compromises cellular and organic functions, leading to a great number of progressive and multisystemic clinical manifestations. Oral manifestations vary according to the type of mucopolysaccharidosis and are of major importance. Most individuals present large mouth, prominent lips, macroglossia, open anterior bite, small and wide mandible, limited mouth opening, gingival hyperplasia, mouth breathing, dental impaction, enamel hypoplasia, diastema with relative microdontia, taurodontism, hyperplasia of dental follicles, and dentigerous cysts. Follow-up should be continuous and multidisciplinary, monitoring patient evolution, foreseeing potential complications, and correcting rising dysfunctions, as well as evaluating therapy effectiveness. Final considerations: there are countless oral manifestations, so the professional is required to know mucopolysaccharidoses and monitor patients from childhood to adulthood, aiming to offer prevention, oral health maintenance, and specialized and multidisciplinary care.

Keywords: Mucopolysaccharidosis. Pathology. Oral health. 


\section{Referências}

1. Giugliani R, Harmatz P, Wraith JE. Management guidelines for mucopolysaccharidosis VI. Pediatrics 2007;120(2):405-18.

2. Gonzalez-Menezes LA, Barcia RA, Diaz RJL. Protocolo de actuación en las mucopolisacaridosis. Protoc Diagn Ter Pediat 2010;1:24-36.

3. Giugliani R, Federhen A, Muñoz-Rojas MV, Alves TV, Artigalás O, Camargo PLL. et al. Terapia de reposição enzimática para as mucopolissacaridoses I, II e VI: Recomendações de um grupo de especialistas brasileiros. Rev Assoc Med Bras 2010;56(3):271-7.

4. Thakur AR, Naikmasur VG, Sattur A. Hurler syndrome: orofacial, dental, and skeletal findings of a case. Skeletal Radiol 2015;44(4):579-86

5. De Santana Sarmento DJ, de Carvalho SH, Melo SL, Fonseca FR, Diniz DN, Bento PM, et al. Mucopolysaccharidosis: radiographic findings in a series of 16 cases. Oral Surg Oral Med Oral Pathol Oral Radiol 2015;120(6):e240-6.

6. Silva LCP, Cruz RA. Doenças do armazenamento lisossômico. In: Silva LCP, Cruz RA. Odontologia para pacientes com necessidades especiais: protocolos para o atendimento clínico. São Paulo: Santos; 2009. p. 109-21.

7. Al-Jawad M, Addison O, Khan MA, James A, Hendriksz CJ. Disruption of enamel cristal formation quantified by synchrotron microdiffraction. J Dent 2012;40(12):1074-80.

8. Byer S, Rozaklis T, Brumfield LK, Ranieri E, Hopwood JJ. Glycosaminoglycan accumulation and excretion in the mucopolysaccharidosis: characterization and basis of a diagnostic test for MPS. Mol Genet Metab 1998;65(4):282-90.

9. Deepak TA, Krishna S, Taretia R. Maroteaux-Lamy Syndrome: a rare case of mucopolysaccharidosis. J Int Oral Health [periódico on-line] 2010 [citado 2015 Outubro 24]; 2(2):[telas]. Disponível em URL: http://www.ispcd.org/userfiles/rishabh01\%20Dr\%20deepak.pdf+html.

10. Sociedade Brasileira de Mucopolissacaridoses - SBMPS. Sobre MPS. Porto Alegre: 2016. [citado Outubro 2016]. Disponível em URL: http://www.ufrgs.br/redempsbrasil/sobremps.php.

11. Antunes LAA, Nogueira APB, Castro GF, Ribeiro MG, Souza IPR. Dental findings and oral health status in patients with mucopolysaccharidosis a case series. Acta Odontol Scand 2013;71(1):157-67.

12. Alroy J, Lyons JA. Lysossomal storage diseases. Jornal of Inborn of Metabolismo and Screening [periódico on-line] 2014. [citado 2016 outubro 31]; 2(2): [telas]. Disponível em URL: http:// iem.sagepub.com/content/2/2326409813517663.full.pdf+html.

13. Macedo AGO, Moraes GVC, Leite FS, Rêgo DM, Pinheiro SFL. Mucopolysaccharidosis type I: Profile of the systemic and conduct dental hospital of pediatrics at the Federal University of Rio Grande do Norte. Int J Dent 2011;10(3):173-9.

14. Giugliani R, Federhen A, Rojas MVM, Viera T, Artigalás O, Pinto LL, et al. Mucopolysaccharidosis I, II and VI: Brief review and guidelines for treatment. Gent Mol Biol 2010;33(4):589-604.

15. Wraith JE. The first 5 years of clinical experience with laronidase enzyme replacement therapy for mucopolysaccharidosis I. Expert Opin Pharmacother 2005;6(3):489-506.

16. Naakamura T, Miwa K, Kanda S, Nonaka K, Anan H, Higash S, et al. Rosette formation of impacter molar teeth in mucopolysaccharidosis and related disorders. Dentomaxillofac Radiol 1992;21:45-9.

17. Neville BW, Damm DD, Allem CM, Bouquot JE. Manifestações orais de doenças sistémicas. In: Neville BW, Damm DD, Allem CM, Bouquot JE. Patologia oral e maxilofacial. 3. ed. Rio de Janeiro: Guanabara Koogan S. A; 2009. p. 677-711.
Endereço para correspondência:

Claudia Marcela Hernández Cancino Endereço: Rua Furriel Luíz Antônio de Vargas, 134, Bela Vista

90470-130 Porto Alegre - RS, Brasil.

Fone: (51) 93647786

E-mail: mcancino401@gmail.com

Recebido: 29/11/2016. Aceito: 11/01/2017. 